\title{
In situ XRD experiments on the growth of expanded austenite using different process gases
}

\author{
Zoltán Balogh-Michels ${ }^{\mathrm{a}, 1^{*}}$, Alexander Faeht ${ }^{\mathrm{b}, 1,2,}$ Simon Kleiner, ${ }^{\mathrm{c},}$, \\ Patrick Margraf ${ }^{\mathrm{d}, 3}$, Alex Dommann ${ }^{\mathrm{e}, 1}$, and Antonia Neels $\mathrm{s}^{\mathrm{f}, 1}$ \\ ${ }^{1}$ Center of X-ray Analytics, Empa Swiss Federal Institute for Materials Science and Technology, \\ Überlandstrasse 129, Dübendorf $\mathrm{CH}-8600$, Switzerland \\ ${ }^{2}$ Institute for Applied Laser, Photonics and Surface Technology, Bern University of Applied \\ Science, Quellgasse 21, Biel-Bienne $\mathrm{CH}-2501$, Switzerland \\ ${ }^{3}$ Härterei Gerster AG, Güterstrasse 3, Egerkingen $\mathrm{CH}-4622$, Switzerland \\ azoltan.balogh@empa.ch, balexander.faeht@students.bfh.ch, csimon.kleiner@bfh.ch, \\ dpatrick.margraf@gerster.ch, ${ }^{\mathrm{e}}$ alex.dommann@empa.ch, ${ }^{\mathrm{f}}$ antonia.neels@empa.ch
}

Keywords: in-situ XRD, nitrocarburizing, expanded austenite, surface treatment, interstitial diffusion

\begin{abstract}
In this work we show our result of in-situ nitrocarburizing and nitriding treatments AISI316L specimens. Part of the samples have been depassivated ex-situ and coated with a Ni layer, while other specimens received in-situ depassivation. Processing was carried out in a custom built reaction chamber attached to a Bruker D8 Advance diffractometer.

We monitored the 111 peak of both the base material and expanded austenite. From the shrinkage of the base material peak the total thickness of the expanded austenite can be determined. Applying both $\mathrm{N}$ and $\mathrm{C}$ resulted in a more than 10 times faster growth of the expanded austenite than with $\mathrm{N}$ only. The growth is thermally activated. The activation energy for nitrocarburizing is $164 \mathrm{~kJ} / \mathrm{mol}$. This is in agreement with the activation energy of the diffusion of interstitials.

Detailed analysis of the expanded austenite peak allowed the derivation of a "master curve" for the composition depth profile. This suggest that two interacting process controls the evolution. The width of the reaction zone is limited by the diffusion at low concentration side. The total concentration is determined by the reaction at the interface.
\end{abstract}

\section{Introduction}

Stainless steels are widely used because of the combination of good workability, reasonable corrosion resistance and affordable price. However their softness cause serious problem when high wear resistance is required, such as for medical prosthetics [1]. Traditional hardening methods, i.e. the formation of a carbide or nitride surface layer might compromise the corrosion resistance, as the formation of chromium-nitride/carbide is preferred [2]. From the mid 80-s nitrogen supersaturation was achieved by low temperature nitrogen ion treatment [3]. In this method the nitrogen is dissolved interstitially which leads to high residual stresses and hardness. The austenitic structure of the material is however conserved [4], thus no withdrawal of chromium takes place. This means that high hardness and good corrosion resistance is possible at the same time.

In the early 2000 s a method to create this so-called expanded austenite via gas phase treatment is patented by Sommers et al. [5,6]. Apart from the easier implementation for industrial procedures, gas phase treatment offers an advantage for systematic scientific investigations too as the chemical potential of a gas mixture is known [6].

In this work we summarize our first results on the processing AISI 316L stainless steel specimens with a purpose built reaction chamber attached to a Bruker D8 diffractometer [7]. We 
carried out nitriding and nitrocarburizing treatment on ex-situ depassivated and nickel coated specimens as well as in-situ depassivation of cold drawn steel specimens.

\section{Materials and methods}

AISI 361L (or 1.4402) type stainless steel specimens were obtained from L. Klein SA. Glow discharge optical emission spectrometry and X-ray fluorescence measurements have been done to test the composition and the measured values were in agreement with the industrial standard [7]. The alloy itself was homogenized at $1050{ }^{\circ} \mathrm{C}$ temperature and cold drawn to 3 meter long rods. From these rods specimens with $15 \mathrm{~mm}$ diameter discs with $1.5 \mathrm{~mm}$ height are cut. The specimens are polished and annealed. For some specimens the oxide was removed via argon ion beam cleaning, which is followed by the deposition of a Ni-film of about $100 \mathrm{~nm}$ thickness.

We used a Bruker D8 Advance diffractometer equipped with a $\mathrm{Cu} \mathrm{K} \alpha$ source for our x-ray diffraction (XRD) investigations. To this system we attached a purpose built reaction chamber, this chamber allowed gas-phase nitriding, carburizing and nitrocarburizing up to $600{ }^{\circ} \mathrm{C}$ processing temperatures (the details of the reaction chamber are described in Ref. [7]).

In a typical processing first an overview XRD spectrum was taken. The intensity ratios of the main peaks of the $\gamma$-Fe are comparable to those of a random oriented powder sample, i.e. no preferred orientation in the drawing direction was detected. The chamber is then purged with $\mathrm{N}_{2}$ gas and the sample is heated to the processing temperature under a flow of nitrogen. After the specimen has reached the processing temperature a 15 minutes long depassivation with $\mathrm{HCl}$ can be applied optionally. Finally the gas composition is adjusted and the XRD spectra are recorded during the processing.

We recorded the $35-45^{\circ}$ range which contained the 111 peak of both the $\gamma$-Fe substrate and the growing expanded austenite. Different literature publications have shown that the boundary between the expanded austenite and the base material is sharp in the micrometer range $[1,8]$. The composition dependence of the diffusion coefficients [9] also favors sharper composition gradients at the low concentration side. This indeed allows the determination of the thickness of the growing expanded austenite via the Lambert-Beer attenuation law $[7,10]$.

$$
\mathrm{I}(\mathrm{x}+\Delta \mathrm{x})=\mathrm{I}(\mathrm{x}) \exp (-\lambda \Delta \mathrm{x})
$$

where $I$ is the intensity $\Delta x$ is the thickness of the expanded austenite and $\lambda$ is the attenuation factor. The growth kinetics of the expanded austenite is fitted by the linear-parabolic model [11].

$$
\mathrm{t}-\mathrm{t}_{0}=0.5 \mathrm{D}^{-1} \Delta \mathrm{x}^{2}+\mathrm{k}^{-1} \Delta \mathrm{x}
$$

where $t$ is the time, $t_{0}$ contains the possible transients and measurement uncertainties, $D$ is parabolic growth rate coefficient while $k$ is the linear growth rate coefficient. $D$ is associated by diffusion described by the continuum model or smoothly varying composition profiles ("diffusion control"). The meaning of $k$ is more elusive, in some cases it can represent non-continuum diffusion $[12,13]$ but especially for gas-solid reactions it can be related to the chemical reaction [14]. Generally speaking, the cause of the $k$ is a limited maximum permeability of a given interface ("interface control").

The expanded austenite peak was fitted via a multilayer model with Gaussian shaped XRD peaks [7]. The area of a given peak is determined by Eq. 1, while the peak width is set to be constant, leaving the peak position (i.e. the average lattice parameter of the layer) as the sole free parameter. A typical fit can be seen on Fig. 1b. 

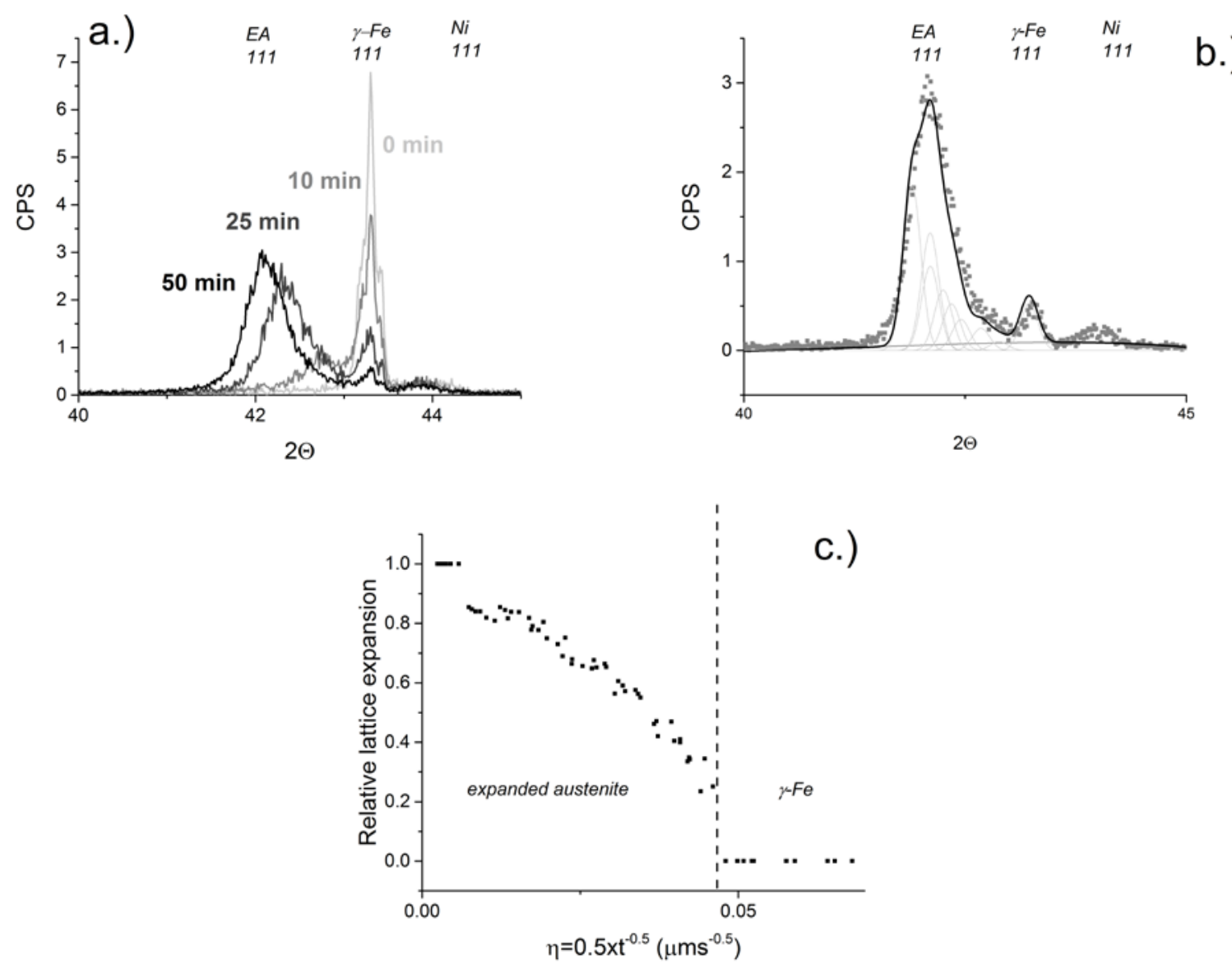

Fig.1: a.) the evolution of the expanded austenite (EA) and the $\gamma$-Fe peak during the processing at $400{ }^{\circ} \mathrm{C}$. b.) an example of the peak-fitting by the multilayer model. c.) the relative lattice expansion plotted as a function of the $\eta$ for the $420^{\circ} \mathrm{C}$ processing. The data is evaluated from multiple spectra.

\section{Results and discussion}

Fig. 1a shows a typical evolution of the XRD spectra. The $\gamma$-Fe signal shrinks while the expanded austenite signal grows and shifts to higher lattice expansion. This shrinkage of $\gamma$-Fe is modelled by Eq. 2. The deviations from the pure parabolic growth were observable [7], however their extent was not large enough for a quantitative study of the interface control. After the transition the diffusion controlled part was stable and we did not experience a significant time dependence of the growth rate coefficient unlike in Ref. [10]. The activation energy for the growth rate coefficient in case of nitrocarburizing is $164 \mathrm{~kJ} / \mathrm{mol}$ [7], this is comparable to the activation energy reported for the interstitial diffusion in $\gamma$-Fe $[15,16]$.

That a single activation energy can describe the process is somewhat surprising, however it is worth noting that activation energy of $\mathrm{C}$ and $\mathrm{N}$ is quite similar in iron $[15,16]$. Moreover there is significant composition dependence of the diffusion coefficient, which means the diffusion at the low diffusivity bottleneck will determine the growth rate of the layer. This means that a change in the activation energy is only expected if the nature of the diffusion bottleneck changes. The simple Arrhenius dependence indicates that slowest diffusion step remained unchanged in this range.

The broad expanded austenite peak was fitted with a multilayer model using the thickness derived from the kinetic experiment as an input parameter. After transforming the depth scale to the Boltzmann-metric $\left(\eta=0.5 \mathrm{xt}^{-1}\right)$ and rescaling the lattice expansion to the lattice expansion relative to that of the first layer we gained a time independent master curve for a respective temperature (Fig. 1c). This curve is composed of three parts, a drop near the surface, followed by a flatter region and a "sharp" boundary between the expanded austenite and the base material. The plot resembles 
the typical concentration profiles of the interstitials (e.g Refs. $[9,10,17]$ ). This emphasize the two controlling bottleneck in the process: the supply side control at the surface and the reduced transport at the low interstitial concentration side. The high diffusivity zone of the expanded austenite layer can adapt itself to the constraints set by two ends.

Fig. 2a. shows a comparison between the growth rate of expanded austenite at $440{ }^{\circ} \mathrm{C}$ when both $\mathrm{C}_{2} \mathrm{H}_{4}$ and $\mathrm{NH}_{3}$ is applied as compared to the $\mathrm{NH}_{3}$ case. The difference is drastic the growth rate coefficient for both gases is $\mathrm{D}=3.4 \times 10^{-14} \mathrm{~m}^{2} \mathrm{~s}^{-1}$ while for the $\mathrm{NH}_{3}$ only case $\mathrm{D}=7.9 \times 10^{-16} \mathrm{~m}^{2} \mathrm{~s}^{-1}$. It is well known from the literature that application of both gases accelerates the process [17].

Comparing our diffusion coefficients for nitrocarburizing and nitriding with the literature results of gas phase nitriding of AISI316 alloys by Christiansen et al. [9] reveals a good agreement for the nitriding (Fig. 2b).

Finally we tested the possibility of in-situ depassivation by HCl-gas. Fig. 3a and $3 b$ shows the difference between the peak shapes and the kinetics for a Ni-coated specimen and the in-situ depassivated ones. For a comparison the shrinkage of the $\gamma$-Fe without depassivation is also plotted to Fig. 3b. To decide whether the kinetics of the Ni coated specimens is enhanced from a catalytic effect or the depassivation process was suboptimal requires further experiments.
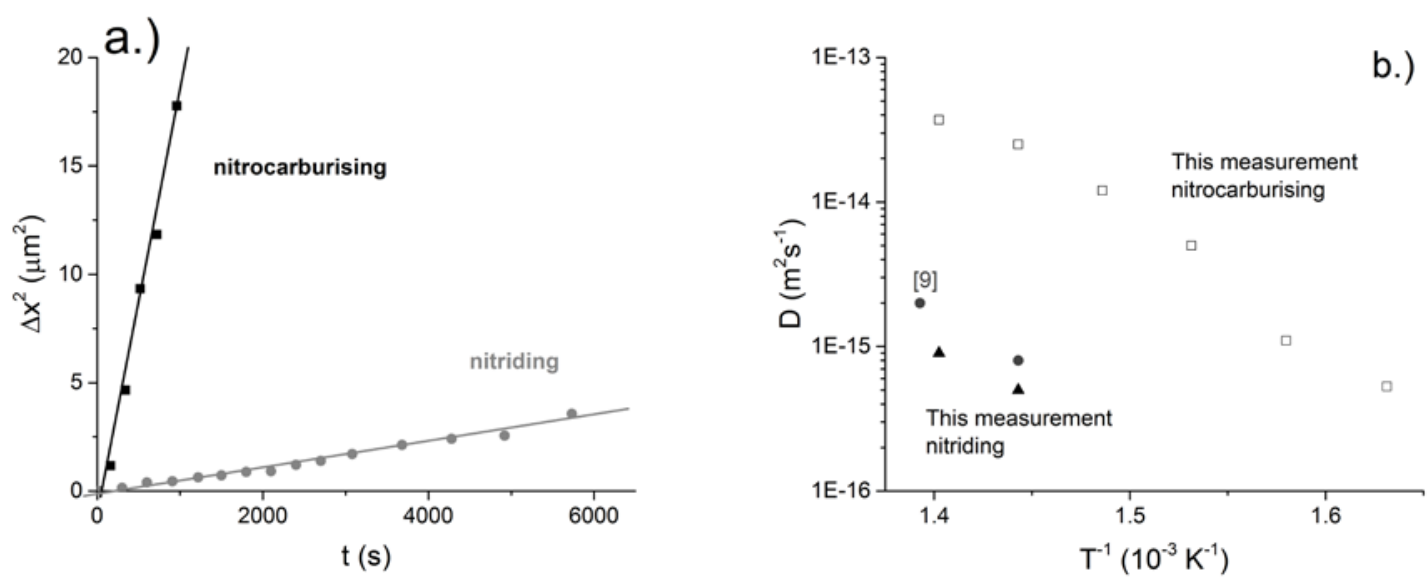

Fig. 2: a.) the evolution of the thickness of the EA layer at $440{ }^{\circ} \mathrm{C}$ for nitrocarburizing and nitriding. b.) a comparison with published result with a similar gas phase treatment on the same AISI 316 type stainless steel.
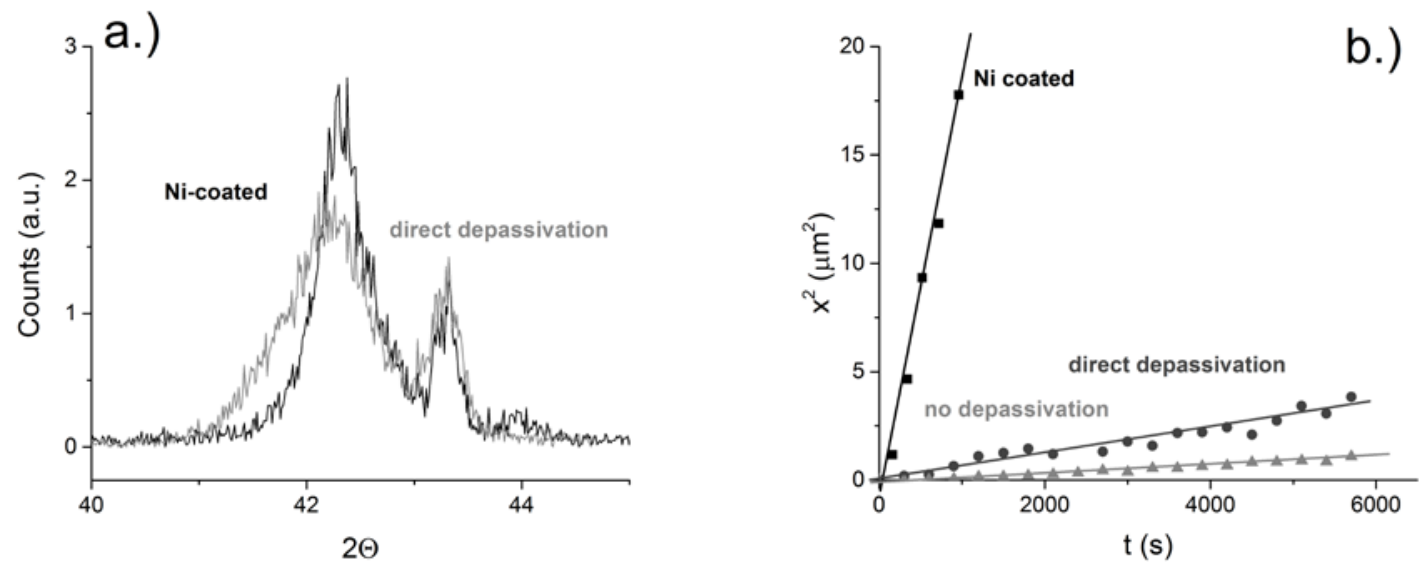

Fig. 3: a.) comparison of the XRD spectra of two $440{ }^{\circ} \mathrm{C}$ processed specimens at similar expanded austenite thickness (the spectra are rescaled) b.) the growth rate of the surface layer for a $\mathrm{Ni}$-coated, a direct depassivated and a passive specimens at $440{ }^{\circ} \mathrm{C}$. The expanded austenite grows faster if ex-situ depassivation and coating is applied. 


\section{Summary}

We carried out gas phase nitriding and nitrocarburizing of stainless steel specimens with a reaction chamber attached to a Bruker D8 Advance diffractometer. This setup allowed the in-situ observation of the formation and growth of the expanded austenite. We tested different specimen types (ex-situ and in-situ depassivated).

According to our results the width of the expanded austenite, if the gas amount is sufficient, diffusion controlled. If both nitrogen and carbon is available the growth rate is significantly higher, the growth rate for nitriding is in agreement with the results of Christiansen et al [9].

The temperature dependence of the growth rate coefficient is Arrhenius-type even for nitrocarburizing. This indicates that the rate controlling step is the same in the temperature range of $340-440{ }^{\circ} \mathrm{C}$. The activation energy of $164 \mathrm{~kJ} / \mathrm{mol}$ is similar to the activation energy of interstitial diffusion.

In-situ depassivation with HCl-gas is possible, but as of now, there is an observable difference between the expanded austenite development process for the in-situ depassivated and the Ni coated samples.

\section{References}

[1] J. Buhagiar, H. Dong, T. Bell, Low temperature plasma surface alloying of medical grade austenitic steel with carbon and nitrogen, Surf. Eng. 23 (2007) 313-317.

[2] J.R. Davis, ASM Speciality Handbook: Stainless steels, ASM International, 1994.

[3] K. Ichii, K. Fujimura, T. Takase, Structure of the nitride layer of 18-8 stainless steel, Technol. Rep. Kansai Uiv. 27 (1986) 135-144.

[4] T. Christiansen, M.A.J. Somers, On the crystallographic structure of S-phase, Scripta Mater. 50 (2004) 35-37.

[5] M.A.J. Somers, T. Christiansen, P. Møller, Danish Patent DK174707B1 and PCT/DK03/00497

[6] T. Christiansen, M.A.J. Somers, Controlled Dissolution of Colossal Quantities of Nitrogen in Stainless Steel, Metall. Mater. Trans. A 37 (2006) 675-682.

[7] Z. Balogh-Michels, A. Faeht, S. Kleiner, A. von Känel, J.-M. Rufer, A. Dommann, P. Margraf, G. Tschopp, A. Neels, In-situ kinetics study on the growth of expanded austenite in AISI 316L stainless steels by XRD, J. Appl. Phys., 122 (2017) 025111.

[8] O. Öztürk, D.L. Williamson, Phase and composition depth distribution analyses of low energy high flux N implanted stainless steel, J. Appl. Phys. 77 (1995) 3839.

[9] T. Christiansen, M.A.J. Somers, Determination of the concentration dependent diffusion coefficient of nitrogen in expanded austenite, Int. J. Mater. Res., 99 (2008) 999-1005.

[10] D. Manova, S. Mändl, J.W. Gerlach, D. Hirsch, H. Neumann, B. Rauschenbach, In situ x-ray diffraction investigations during low energy ion nitriding of austenitic stainless steel grade 1.4571, J. Phys. D: Appl. Phys., 47 (2014) 365301.

[11] U. Gösele, K.N. Tu, Growth kinetics of planar binary diffusion couples: "Thin-film case" versus "bulk cases", J. Appl. Phys. 53 (1982) 3252-3260.

[12] Z. Erdélyi, D.L. Beke, P. Nemes, G.A. Langer, On the validity of the continuum approach for nonlinear diffusional mixing of multilayers, Philos. Mag. 79 (1999) 1757-1768

[13] Z. Balogh and G. Schmitt, Diffusion in Metals and Alloys, in D.E. Laughlin and K. Hono (Eds), Physical Metallurgy Ed. 5, Elsevier, Amsterdam, 2014, Ch. 5.7.1 pp. 525-535.

[14] B.E. Deal, A.S. Grove, General relationship for the thermal oxidation of silicon, J. Appl. Phys. 36 (1965) 3770-3778.

[15] P. Thibaux, A. Métenier, C. Xhoffer. Metall., Carbon Diffusion Measurement in Austenite in the Temperature Range $500{ }^{\circ} \mathrm{C}$ to $900{ }^{\circ} \mathrm{C}$, Mater. Trans. A 38 (2007) 1169-1176.

[16] R.P. Smith, Diffusivity of carbon in gamma iron-cobalt alloys, Trans AIME, 230 (1964) 476. 
[17] D. Wu, Y. Ge, H. Kahn, F. Ernst, A.H. Heuer, Diffusion profiles after nitrocarburising austenitic stainless steel, Surf. Coat. Technol. 279 (2015) 180-185. 